\title{
MORAL OUTRAGE PORN
}

\section{Thi Nguyen and Bekka Williams}

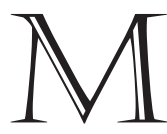

OST ACADEMIC DISCUSSION about pornography has focused on the term in its, shall we say, classical use: pornography of a sexual nature.

But right under the nose of the academic discussion, a secondary usage has evolved. Examples include, but are not limited to, "food porn," "closet porn," and "real estate porn." This usually refers to photographs (but also sometimes films and textual descriptions) of exquisitely prepared food, carefully arranged closets, and beautifully decorated apartments and homes. These representations are typically found and consumed via magazines and online sites dedicated to such images. Often, these images are of the kind of thing we would rarely be willing or able to get for ourselves, like photographs of meals at vastly expensive restaurants or airy Manhattan apartments far out of our economic grasp. Sometimes, these images are of things that we can obtain, but feel vaguely guilty about consuming — such as glistening, artery-clogging burgers. In other cases, they are perfectly ordinary things, but we enjoy looking at pictures of them anyway for some reason: close-up photos of a juicy steak or interior shots of other beautiful houses in our neighborhood that we could have purchased, but did not.

Perhaps this usage began as a metaphor or a joke, but it has quickly come to have a life and meaning of its own. Consider: we could introduce a new application of the term without further explanation and anybody who trafficked in modern colloquialisms would know exactly what we meant. For example, "I was up late last night looking at headphone porn," or "Have you seen that new site of high-end Japanese raw denim? Great fading porn," or "I'm feeling sad. Everybody please cover my Facebook with baking porn." ${ }^{1}$ More importantly, we think this neologism captures something very important about the way that we sometimes relate to, and use, representations. The usage, we suggest, adapts a

1 In a 2018 episode, Saturday Night Live opened with comic Alex Moffat (in the guise of Anderson Cooper) referencing "impeachment porn"-an utterly new usage, but one that was immediately comprehensible (season 43, episode 16, aired March 3, 2018). 
part of the traditional concept of pornography-a part that is conceptually separable from sexuality. In using representations as sexual pornography, food porn, or real estate porn, we usually have no intention of engaging with the conveyed content of the representation. When we engage with pornography as such, we are not aiming to actually seek out sex with the porn star, actually go to that restaurant, or actually buy that house. Rather, we are using the representation itself for immediate gratification.

The first task of this paper, then, is to offer a conceptual analysis of this new use of "porn" in the generic sense. Our account will be, loosely, that a representation is used as generic porn when it is engaged with for the sake of a gratifying reaction, freed from the usual costs and consequences of engaging with the represented content. We can engage with sexual pornography without the need to find and engage with a sex partner; we can engage with food porn without worrying about the cost or health consequences; we can engage with real estate porn without having to clean and maintain all that spotless gleaming wood. Our claim is not specifically about the nature of sexual pornography, nor are we attempting to claim any new insight into that concept. Rather, we think the new generic usage has seized on a usefully exportable part of the cluster of ideas that surrounds sexual pornography, and cleaved it off. This conceptual analysis of generic porn is useful, we take it, because it draws our focus to a distinctive form of relationship that we have with certain representations.

The use of generic porn is not necessarily problematic, and many forms of such gratification are harmless. For example, C. Thi Nguyen's spouse has a particular affection for something she calls "organization porn," exemplified by the Things Organized Neatly page on Tumblr-a page full of an endless succession of images of pleasing organization, such as a thousand colored pencils arranged perfectly by shade, or a pile of oddly shaped pieces of wood stacked into a perfect square. She says that such images calm her down immediately when she is feeling overwhelmed by anxiety and the chaos of her life. We take it as a datum that her use of this site is, at least in the moral sense, unproblematic. But we think some specific types of generic porn are problematic-epistemically, morally, or both.

We will further demonstrate the usefulness of the concept of generic porn by using it to isolate another type of such porn, which has not yet been singled out: moral outrage porn. Moral outrage porn, as we understand it, is representations of moral outrage engaged with primarily for the sake of the resulting gratification, freed from the usual costs and consequences of engaging with morally outrageous content. The gratifications might include, among other things, a sense of moral superiority or smugness, the comforting sense of clarity that 
arises from moral certainty, and the sheer pleasure of the feeling of outrage itself. $^{2}$ We suspect that a significant amount of the activity on Facebook, Twitter, and other forms of social media might plausibly count as moral outrage porn, as does much of the content on many partisan news outlets. We will also argue that moral outrage porn is potentially more dangerous than other sorts of generic porn. Some kinds of porn are mechanistic - that is, they bring about their gratifications without requiring that their user engage in any sort of belief or belief-like states. Food porn, real estate porn, and many uses of sexual pornography are mechanistic in this way. But moral outrage porn is non-mechanistic; it is an essentially cognitive form of porn. One must engage in a belief, or belief-like state-a state of judging something to be morally bad, or something very much like this-in order to acquire the desired gratification. And this use, we will argue, is a bad thing, other things being equal. Let us be clear: our purpose here is not to condemn the use of moral outrage in moral and political discourse. Moral outrage is essential, when it proceeds from nuanced moral engagement, leads to moral action, and is aimed at the genuinely morally outrageous. Our goal here is to distinguish such authentic engagements with moral outrage from the use of moral outrage porn. Moral outrage porn, we will suggest, invites its users to seek simplified moral representations of the world, and to simplify their own moral beliefs in order to maximize the gratifications of outrage.

Finally, we offer a unified account of why some uses of porn seem benign while others seem deeply problematic. Using porn involves a particular form of instrumentalization of the porn itself. It may also encourage users to instrumentalize the kinds of real-world objects represented in the porn. Using porn is problematic when those sorts of instrumentalizations are problematic. When such instrumentalization is harmless, then using porn is (other things being equal) harmless. Using food porn is harmless because there is nothing wrong with instrumentalizing representations of food or food itself. On the other hand, there is something very wrong with instrumentalizing morally rich descriptions of the world.

2 One set of representations often described as "revenge porn" is like this. Consider, for example, the use of the term revenge porn in discussions of recent complaints against comic Aziz Ansari. (See, for example, Abcarian, "Is Aziz Ansari a Victim of 'Revenge Porn' or a Perpetrator?”; Flanagan, "The Humiliation of Aziz Ansari”; and Ham, "Ansari Isn't the First Victim of \#MeToo Revenge Porn, but He Should Be the Last.") Please note, however, that we are not discussing another common use of the term revenge porn, where this describes dissemination of sexual images of a prior partner for purposes of revenge/embarrassment. (Instances of the two usages can overlap, but they typically do not.) 


\section{PORNOGRAPHY AND GENERIC PORN}

Let us first establish some terminologies of convenience. We will reserve the term pornography for the traditional, sexual usage and use porn to refer to our new, generic sense. ${ }^{3}$ Let us start by charting some uses of this newer sense of "porn." "Food porn" seems to be among the earliest usages of the generic sense of "porn," and the usage is now quite widespread. Consider, for example, the site FoodPornDaily_-subtitled "click, drool, repeat." ${ }^{4}$ The main page of the site consists of single large close-up shots of food, like juicy fruit cobblers or extra-cheesy nachos. The user stares at the picture for a while, and, at their leisure, clicks on it, which immediately refreshes the page with another randomly selected close-up shot of food. Though the use of "porn" in this case may contain a bit of self-mockery or a self-admission of guilt, the usage is not typically condemnatory, as can be gathered by the gleeful self-identification of many food porn fans as such. Similar openly acknowledged usages of porn, under that very term, can be easily found for real estate porn, closet porn, cabin porn, and various kinds of fashion porn.

Other uses are more condemnatory. For example, the term "poverty porn" has come to be used for a certain indulgent use of images and stories of poverty. Here is an example and explanation from recent journalism:

In case you hadn't noticed, poverty is entertaining. "Poverty porn" refers to both Westerners' portrayal of global inequality, and also to the distorted presentation of disadvantage by the advantaged. Like mainstream sexual porn that produces sexualised images from the male gaze for male gratification, poverty porn produces objectifying images of the poor through a privileged gaze for privileged gratification. ${ }^{5}$

Similarly, pictures of urban decay have been called, in a critical mood, "ruin porn." Again, from recent journalism:

"Ruin porn" is based purely on aesthetics and is almost always devoid of people. Employing the mismatched spoils of history, ruin porn ignores and overwrites the voices of those who still call Detroit home. When its ruins are fetishised as art, these injustices are, at best, ignored, and, at

3 We in no way mean to claim here that these usages perfectly track natural usages; we introduce them for the sake of writerly brevity.

4 FoodPornDaily, http://foodporndaily.com/.

5 Threadgold, “'Struggle Street' Is Poverty Porn with an Extra Dose of Class Racism.” 
worst, mimicked. They ignore the humanity of residents' current struggles, while replicating the history that created them. ${ }^{6}$

But, one might ask, why call it porn at all? The suggestions from both journalistic sources recorded above are remarkably harmonious. Ruin porn and poverty porn are exploitative presentations of impoverished people and ruined cities, used for some sort of gratification. The parallel to traditional accounts of sexual pornography is, at least in broad outlines, obvious.

Notice that the quoted discussion of "poverty porn" invokes the notion of objectification-well-familiar from feminist criticisms of pornography. The parallel between sexual pornography and generic porn is quite striking in the poverty porn case, because poverty porn also focuses on images of people. Here, the claim that they both share an objectifying gaze is plausible. But the notion of objectification, in its barest form, will not help us with developing an account of generic porn-since many of the subjects of such porn are, literally, objects. One cannot reduce a closet to an object because it already is an object, and any accurate representation of the closet will present it as such. Part of the usage of "porn" is to imply that it is a distinctive sort of representation. Not all pictures of real estate are real estate porn and not all pictures of closets are closet porn, though both porn and non-porn images can correctly present what they depict as objects. Thus, the brute notion of objectification will not help us isolate the distinctive quality of generic porn or explain why some forms of food photography count as food porn while others do not.

More help will come for our particular interests if we turn from the feminist discussion of pornography, with its particular focus on sex, sexuality, and human bodies, to the smaller and less traveled discussion of pornography from the aesthetics literature. ${ }^{7}$ Here, the conversation has been one that attempts to distinguish between the concept of "pornography" and the concept of "art"often focusing on trying to isolate the conceptual difference between an artistic nude (perhaps even an erotic one) and pornography. Much of that debate has concerned the question of whether the concepts of art and pornography are essentially incompatible. We will remain neutral on that debate for the purposes of this paper, but the conceptual territory that has been explored during the debate will be useful to us. As Anne Eaton and Hans Maes point out, artistic nudes can

6 Doucet and Philp, “In Detroit 'Ruin Porn' Ignores the Voices of Those Who Still Call the City Home."

7 Andrew Kania has provided a useful discussion of the different themes, framing issues, and results across the feminist discussion and the aesthetics discussion ("Concepts of Pornography”). 
also be problematically objectifying and misogynistic. ${ }^{8}$ Thus, the conceptual distinction between erotic art and pornography must turn on something over and above objectification and misogyny, or at least the distinction must be more fine-grained.

One way to make the distinction, according to Maes's classificatory scheme, has been to distinguish pornography in terms of its prescribed response. George Steiner argues that pornography leaves nothing up to the imagination, while art invites the audience to enter into a jointly creative effort. ${ }^{9}$ The thought goes something like this: art invites all kinds of complex responses. In fact, the freedom of our response is part of the value of art, whereas pornography is made for, and used for, one particular response. Pornography has a simple and mechanistic relationship to its users' desired response. From this observation, we can make a larger point. Pornography has purely instrumental value. It is there to provoke a response, and once this has been achieved, we discard it. Art, on the other hand, is intrinsically valuable. This is why, suggests Maes, we speak of consuming pornography and of appreciating art.

A recent variation on this approach pays special attention to the different kinds of relationship between a representation and its medium. With art, we care about the way that the content is presented-the technique, the use of the medium - but with pornography, we do not. This approach has many proponents and many fine-grained variations, but let us take Christy Mag Uidhir's analysis as our touchstone here. ${ }^{10}$ Pornography, says Mag Uidhir, is valuable insofar as it achieves its purpose of sexual arousal in a "manner-inspecific" way, whereas art is valuable insofar as it achieves its purpose in a "manner-specific" way. ${ }^{11}$ With art, we care about all the subtleties of how an artwork achieves its effects-about the delicacy of the brushwork, or the interesting framing — whereas with pornography, all we care about is the brute fact that we get that desired response. Thus, according to Mag Uidhir, even if there is erotic art whose purpose is sexual arousal, it differs from pornography in the following way: erotic art is valuable for the way in which it produces the sexual arousal-its usage of, say, photographic or painterly technique - where pornography is valuable just if it does the job. (Mag Uidhir is building from Jerry Levinson's account, according to which pornogra-

8 Eaton, “A Sensible Antiporn Feminism”; Maes, "Who Says Pornography Can't Be Art?” 22.

9 Steiner, "Night Words," 210.

10 For the variations, see see Davies, "Pornography, Art, and the Intended Response of the Receiver." 
phy simply presents its content and gets out of the way, whereas, with art, we care how that content is presented. $)^{12}$

Perhaps here it is worth going back as far as Schopenhauer. As Alex Neill notes, Schopenhauer contrasts the much-vaunted aesthetic category of the sublime with what he calls the merely charming or attractive. ${ }^{13}$ The charming was not a kind of content, but a style or manner for portraying contents. The charming cannot be experienced aesthetically, says Schopenhauer, because it is designed to excite desire in the beholder, and desire makes impossible the willless, contemplative attitude that Schopenhauer takes to be essential to aesthetic experience. Strikingly, Schopenhauer picks out two subjects for his disdaincertain historical manufacturers of nudes who arranged their subjects precisely to excite lust, and certain reprehensible Dutch still life paintings of food that depicted the food in a manner that "necessarily excite[s] the appetite," and from which the spectator is "positively forced to think of [its] edibility." ${ }^{4}$

From both of these threads we can draw some useful lessons for our project. In general, what unifies these accounts is a sense that pornography offers something like a mechanistic or simplistically functional relationship to a representation. We use that representation to get a particular effect and we value it because it reliably gets that effect. And pornography is always contrasted with some other representative practice that supports, from certain lights, a fuller and richer relationship. Non-pornographic artistic representation, by varying accounts, leaves our imagination free, lets us be contemplative, or invites contemplation of the subtleties of the manner and form of its presentation. Roger Scruton, in fact, criticizes pornography, not for failing to be art, but for failing to work toward full personal relationships. Pornography gets us only sensations, whereas sexual desire, in its most mature and developed form, moves us toward deep interpersonal relationships. ${ }^{15}$

Perhaps one might wish to reject Scruton's claim that the purpose of sexual desire is always deep interpersonal relationships. Even then, a version of the point still holds. Using pornography involves a thinner and less rich interpersonal interaction than sex. Using pornography involves no interaction and no mutual responsiveness. ${ }^{16}$ Something about this parallel is surely captured in the generic usage of "porn." Food porn merely stimulates us; it does not bring us

\section{Levinson, "Erotic Art and Pornographic Pictures.”}

Neill, “The Pornographic, the Erotic, the Charming, and the Sublime," 49.

Schopenhauer, The World as Will and Representation, 207-9.

Scruton, “The Moral Birds and the Bees."

It is thus unsurprising that it is exactly this lack of mutual responsiveness in sexual cases that leads Nagel to classify such cases as "perverse” ("Sexual Perversion”). 
nourishment. Conversely, when my friend enthusiastically texts me pictures of the beautiful vaulted ceiling and the warm wooden hallways of the house that she has just bought, saying that, for the first time in her life, she feels at home, those pictures are most decidedly not real estate porn. Food porn, real estate porn, and ruin porn are unified in being shorn of context and consequence-in being used to satisfy some desire in a reliable, simple, and functional way. Our relationship to porn is sharply and straightforwardly instrumental. This observation will eventually help us to offer a unified account of why some sorts of porn are so troubling, and others are not-and help us to say why. But before we can do that, we need to provide a clearer account of what, exactly, porn is.

\section{TOWARD A DEFINITION}

We would like, now, to offer a definition of "porn," in the generic sense. We adapt our definition from Michael Rea's account of pornography. ${ }^{17}$ We happen to think that this is a particularly good account of sexual pornography, but the reader need not share that view. What is most important is that Rea's account captures something central to what we have been discussing, and references to sexuality and obscenity are not fundamental to the account.

Rea's account is one that takes the use of pornography by its audience as the primary concept. He then treats "pornography" as a secondary concept, defined in terms of something's being used as pornography.

Rea defines use-as-pornography in the following way:

Part 1: $x$ is used (or treated) as pornography by a person $S={ }_{\mathrm{DF}}(\mathrm{i}) x$ is a token of some sort of communicative material (picture, paragraph, phone call, performance, etc.), (ii) $S$ desires to be sexually aroused or gratified by the communicative content of $x$, (iii) if $S$ believes that the communicative content of $x$ is intended to foster intimacy between $S$ and the subject(s) of $x$, that belief is not among $S$ 's reasons for attending to $x$ 's content, and (iv) if $S$ 's desire to be sexually aroused or gratified by the communicative content of $x$ were no longer among $S$ 's reasons for attending to that content, $S$ would have at most a weak desire to attend to $x$ 's content. ${ }^{18}$

To gloss this account, a piece of communicative material is used as pornography if its user's primary interest in engaging with that material is sexual arousal or gratification. Once the concept of something's being used as pornography is established, Rea defines "pornography" straightforwardly:

17 Rea, "What Is Pornography?"

18 Rea, "What Is Pornography?" 120. 
Part 2: $x$ is pornography $=_{\mathrm{DF}}$ it is reasonable to believe that $x$ will be used (or treated) as pornography by most of the audience for which it was produced. ${ }^{19}$

A virtue of Rea's account is that it makes sense of the relationship between pornography proper and the usage of repurposed pornographic artifacts. For example, if hackers break into a film star's computer, steal some medical pictures, and then distribute them for the purposes of sexual gratification, then those pictures are not pornography, but they will be used as pornography. Rea's condition (iii) is intended to distinguish between pornography and sexually explicit intimate communications between romantic partners. It is, we suggest, a relative of Scruton's thought that pornography is a shallower use of sexual desire than are relationships. It also allows us to finely differentiate between pornographic and non-pornographic uses of the same material. For example, suppose that one sends one's romantic partner revealing pictures of oneself. If they use those pictures for sexual arousal, but that arousal plays a part in building and furthering intimacy, then their use of the pictures is not pornographic on Rea's account. If, however, one's partner saved those photographs and used them for immediate gratification after the relationship had ended, then that use would count, on Rea's account, as treating-as-pornography.

We take Rea's account to be an excellent one from which to build; it will help us to crystallize the various associations we charted above. We make the following changes to generalize the account. We substitute for the specific notions of sexual arousal and sexual gratification the general notion of gratifying reactions. A reaction is gratifying when we take some positive enjoyment or pleasure from the reaction itself. Furthermore, Rea's condition (iii) is quite specific to the case of sexuality and its role in human relationships. To generalize the underlying idea, what seems to unite all the cases of porn is some disengagement from the usual complexities, entanglements, difficulties, and responsibilities of the represented content.

Finally, we shift from the notion of "communicative material" to "representations" because the notion of a representation is thinner than the notion of communicative material and will capture an appropriately wide array of cases. For example, if I take a picture with my phone to remember a delicious piece of cake for myself, that picture is clearly a representation, but not clearly a piece of communicative material. I can surely use that photo as food porn. Similarly, suppose I bump my phone and accidentally send a picture of the exquisite meal 
I am enjoying to a friend. That is certainly a representation, but not obviously a communication, and it also could be used as food porn.

Thus, following Rea, we define treating-as-porn in the following way:

Treating a representation as $\Omega$-porn $=_{\mathrm{DF}}$ using the content of a representation of $\Omega$ primarily for the purpose of generating one's own gratifying reactions, freed from the typically attendant consequences and effort of engaging with $\Omega$.

We include "and effort" because there are cases of $\Omega$-porn where the effectiveness of the porn hinges at least in part on avoiding aspects of the process of engaging with $\Omega$, rather than avoiding the consequences of engaging with $\Omega$.

We then define generic porn in the following way:

$x$ is $\Omega$-porn $=_{\mathrm{DF}} x$ is a representation where it is reasonable to believe that $x$ will primarily be used (or treated) as $\Omega$-porn by most of the audience for which it was produced or transmitted.

Our account adds to Rea's the demand that $x$ will primarily be used as $\Omega$-porn. This strikes us as a necessary amendment to capture the complexities of the generic use of the term "porn." For example, Cezanne's still-life paintings of fruit might primarily be interacted with as art, and secondarily inspire a gratifying appetitive response shorn from the entanglements of actually eating. It would be strange to call those paintings porn because their status and function as art is dominant. Note, however, that it is still open for particular audience members to primarily use those paintings as porn, without the paintings actually being porn.

Notice that we have added the notion of "transmission" to Rea's notion of production. This, we think, captures an additional possibility that has become particularly salient in the current socio-technological media context. In many cases, content aggregators have brought together representations that were not originally produced for the sake of being used as porn, but that have been aggregated or retransmitted for the sake of usage as porn. For example, some blogs collect particularly luscious real estate photos from sites that posted those photos for the sake of sale, but where the blogs have collected the most porn-worthy shots.

Finally, our account of treating-as-generic-porn drops an equivalent to Rea's condition (iv) — the requirement that if a user's sexual interest lapsed, the user would have little desire to continue to attend to the content. Even if (iv) were plausible in cases of sexual pornography, it is highly implausible in important cases of generic porn. As Stephanie Patridge notes, we can have multiple rea- 
sons for attending to a representation..$^{20}$ Enjoyment of sexual representations may sometimes overlap with other motivations for attending to these representations, and individuals may still have non-pornographic reasons for attending to a representation in the (counterfactual) absence of the pornographic reasons. For example, suppose that we enjoy impeachment porn in large part because of the moral importance we attach to problems with the current administration. The very importance we attach to these problems likely grounds a reason for us to attend to newsfeeds reporting new problems for the administration, independent of the gratifying reactions that these reports facilitate. (We suspect that this grounding relation is especially common in cases of moral outrage porn, which we discuss below.) Notice, however, that even if a piece of news could be used as porn, it still might not count as porn, if it were not reasonable to believe that it would be so used by most of its intended audience.

After all these complexities, let us also offer a slightly more portable, albeit less exact, version of our account:

Portable version: $\Omega$-porn is representations of $\Omega$ used for immediate gratification, while avoiding the usual costs and consequences of actually engaging with $\Omega{ }^{21}$

A nice upshot of our account is that Rea's notion of pornography turns out to be a special case of generic porn, and it satisfies our definition of pornography in a way that highlights the parallels between sexual pornography and generic porn. On our view, sexual pornography is a representation of sexual content, primarily used for the purpose of a gratifying reaction, freed from the usual effort and consequences of sexual interaction. ${ }^{22}$ Food porn is a representation of food, primarily used for the purpose of generating gratifying reactions like pleasurable hunger or culinary excitement, freed from the various efforts of making food or going to a restaurant, and consequences regarding price and nutrition. (This explains why food porn is so often a representation of very unhealthy, very expensive, and/or very difficult-to-prepare food.) Real estate porn is a representation

20 Patridge, "Exclusivism and Evaluation," 50.

21 Note that this version elides some of the linguistic complexity of the full definition of porn. This is meant only as a writerly convenience; we mean throughout to be invoking our full definition of porn.

22 Note that our definition demands only that the use-as-porn is in fact (or expects to be) freed from the usual effort and consequences, not that the user of porn would prefer to be so freed. Somebody using sexual pornography might have preferred to actually have sex and be entangled with the costs and consequences, but still counts as using-as-porn because, in fact, they have not been so entangled and have no expectation of being so entangled in connection with using the pornography. 
of real estate, primarily used for the purpose of generating gratifying reactions, freed from the attendant efforts and consequences of purchasing and maintaining real estate. (This explains why real estate porn is so often of a representation not only of expensive real estate, but of hard-to-maintain surfaces and materials, like all-white upholstery.) Poverty porn is representations of impoverished people, primarily used for the purpose of various gratifying reactions - like the pleasures of sensations of sentiment and empathy - while freed from the attendant effort and consequences of actually having to morally engage with and face the prospect of relieving such poverty. (This explains why pictures of impoverished people published on charitable donation websites are likely not poverty porn, but those same pictures repurposed in a certain sort of travel magazine very likely might be.)

\section{MORAL OUTRAGE PORN}

We have identified what we take to be the concept underlying this new colloquial usage. And this new colloquial usage, we think, has come about for a very good reason. It picks out a clear, useful, and morally and practically relevant category. To demonstrate the account's conceptual fecundity, we will use it to identify a novel form of porn - one that, we hope, will help us to make sense of the world.

We suggest a new category of porn: moral outrage porn. Moral outrage porn is representations of moral outrage primarily used for the sake of the resulting gratification, where the user engages with the representation freed from the usual consequences and efforts of engaging with morally outrageous content. The term "representations of moral outrage" deserves some clarification. There are several forms. One is the representation of expressions of moral outrage-such as angry tweets expressing moral outrage at some event. Another is the representation of states of affairs as morally outrageous - such as a morally charged, condemnatory description of a political event. We use such representations as moral outrage porn when we engage with them primarily for the sake of a gratifying reaction, freed from the usual consequences and efforts. Such representations are moral outrage porn when it is reasonable to think that they will primarily be put to such uses. Most importantly, using such representations as moral outrage porn often involves engaging with them without applying the epistemic standards of veracity or worrying about the consequences of entertaining such representations.

One might now reasonably begin to suspect that a significant amount of the content of social media is, at present, moral outrage porn. A paradigmatic example of moral outrage porn is the content of certain politically partisan news sites 
and social media feeds, which continually present inflammatory articles targeting some political enemy. Recall that one of the suggested accounts of sexual pornography was that it is used for its capacity to reliably provoke some specific effect-as opposed to art, which leaves the audience free to respond in a variety of ways and is sought out for that very capacity. Levinson suggests, in fact, that the very complexities and subtleties that make for artful presentation get in the way of the simple, reliable, mechanistic provocation of sexual responses of pornography. When we want porn, we do not want artfulness. We just want for pornography to do its job and then get out of the way. ${ }^{23}$ We can find a similar phenomenon with moral outrage porn. When one interacts with the news in a non-porn way, one looks for the facts, in their full complexity, and engages with them as purportedly true statements about the world. This sort of interaction leaves the door open for one to encounter unsettling ideas-unexpected evidence, challenging considerations. On the other hand, when one uses the news as moral outrage porn, one comes to it hoping, consciously or subconsciously, that it will reliably provide the gratifications associated with moral outrage. ${ }^{24}$ This would likely lead one to be largely disinterested in complex presentations of morally ambiguous situations, because that would interfere with getting reliably to that gratifying moral outrage. Such a user of moral outrage porn would, then, seek out reliable sources of simplistic and predictable moral descriptions of the world. ${ }^{25}$ They would avoid morally rich representations, which might lead to complex and unpredictable emotional and intellectual responses.

What makes something moral outrage porn then is the interest in using morality for gratification on the part of its users. A news item may indeed invite moral outrage, but insofar as we reach that moral outrage through a full-blooded and nuanced moral engagement—insofar as we are seeking moral truth and not using our morality reactions for pleasure - then we are not using it as moral outrage porn.

Notice, too, that our definition of "porn" includes things that are transmitted, and not necessarily produced, for the sake of treatment as porn. Think about

23 Levinson, "Erotic Art and Pornographic Pictures," 232-33.

24 See empirical work by Green et al. suggesting a tendency for individuals to want to read moral-outrage-inducing articles in order to feel good about themselves ("Self-Enhancement, Righteous Anger, and Moral Grandiosity"). Also see Pizarro and Baumeister, "Superhero Comics as Moral Pornography," for a discussion of the gratification of moral judgment and categorization; as well as Rothschild and Keefer, "A Cleansing Fire," for evidence suggesting that expressing moral outrage can be effective in reducing feelings of personal guilt.

25 For an excellent discussion of superhero comics as a specific example of such moral simplification for enjoyment purposes, see Pizarro and Baumeister, "Superhero Comics as Moral Pornography," 29-31. 
moral outrage porn newsfeeds, which pick stories from more informationally and morally rich resources. For example, a highly partisan newsfeed could simply repost news from more neutral news sites, but cherry-pick the most inflammatory stories. That cherry-picked feed creates moral outrage porn through contextual aggregation. It might be that no particular news item on such a biased feed is moral outrage porn on its own, but the filtered, preselected assemblage may compositely be moral outrage porn. ${ }^{26}$

\section{DANGERS OF MORAL OUTRAGE PORN}

Though porn, in the generic sense, is not necessarily dangerous or morally problematic, we think that moral outrage porn, in particular, is problematic. First, the use of moral outrage porn is a form of epistemic bad faith. If we adopt beliefs simply or primarily for the sake of their pleasurable resulting outrage, rather than for their putative veracity, then this is clearly a violation of any number of plausible epistemic standards. Second, in many cases when we indulge in using moral outrage porn, we are not adopting any new beliefs, but are instead using the moral values that we already have for the sake of generating personal gratification. We will argue that this, too, is a highly suspect and problematic practice.

First, we propose a distinction between two sorts of porn: mechanistic porn and cognitive porn. In mechanistic porn, one achieves gratification from experiencing a representation without needing to take on any specific beliefs regarding the representation's truthfulness or accuracy. We take food porn to be an almost entirely mechanistic form of porn; much sexual pornography is similarly mechanistic. ${ }^{27}$ In order to be gratified by cognitive porn, however, one must seriously entertain the legitimacy of some belief relevant to the represented content. In the case of moral outrage porn, one must usually seriously entertain some moral belief arising from the represented content, or seriously entertain some moral belief that applies to the represented content. ${ }^{28}$

26 This raises the possibility of algorithmically generated moral outrage porn, in which automatic filtering effects from technological agents like Google Search algorithmically generate resources which it is reasonable to believe that its audience will use as porn. See Pariser, The Filter Bubble; Miller and Record, "Justified Belief in a Digital Age"; Watson, "Filter Bubbles and the Public Use of Reason"; and Nguyen, "Echo Chambers and Epistemic Bubbles." Furthermore, if it is not already clear, we think that there is moral outrage porn aplenty across the political spectrum.

We accept, however, that at least some sexual pornography is (at least to a significant degree) cognitive.

28 Consider, also, the recent coinage of the term "justice porn," which is representations of wrongdoers getting their immediate, and often violent, comeuppance. Justice porn is almost 
Let us start with a paradigmatic case of moral outrage porn: a website whose readership is entirely of political party $A$ posts detestable quotations from political leaders of political party $B$, where that readership is primarily interested in using those quotations for the sake of pleasurably stoking their moral outrage. In the usual case, there are two components: (i) a particular judgment concerning the represented incident, which is grounded in (ii) some moral value that readers accept. Intuitively, there seems to be something quite wrong with the use of moral outrage porn in this case. It seems like we are not so much inhabiting our moral beliefs as we are taking advantage of them for self-gratification.

But what, really, is the problem with that? It cannot just be that one is not taking one's moral beliefs sufficiently seriously. In fact, one typically needs to have a certain degree of moral belief and commitment in order to attain the desired gratifications. Holding one's moral beliefs with unswerving seriousness and commitment can actually make it easier to achieve the various gratifications of emotional security, clarity, comfort, and superiority.

Let us start by considering the epistemic problems involved with using moral outrage porn. There are two possibilities here. First, the user of moral outrage porn could be adopting a new moral view in order to be gratified. Second, the user could be gratified by the exercise of a moral view they already accept. Either case is problematic.

Suppose one adopts a new moral view simply in order to be gratified. The problem here is clear: one is adopting a belief or set of beliefs for non-epistemic reasons. ${ }^{29}$ The reasons of gratification urge one toward a different set of moral beliefs than the reasons of moral veracity. Imagine, for the moment, that one set out to develop a set of moral beliefs so as to maximize one's possibility for pleasing moral outrage. The moral system one would develop would likely be clear, strident, and demanding, so as to maximize the incidence of moral outrage. It would likely admit of few ambiguities or difficulties, for the purpose of maximizing the possibility of clear, undiluted outrage and its associated pleasures. This sort of procedure obviously violates any number of epistemic norms and

certainly another example of cognitive porn. In order to enjoy the representation of (say) a just punishment as just, it is plausible that one must accept, at least while enjoying the representation, that the retribution was justified. Thus, insofar as a representation is used as justice porn, the user must have, or at least entertain, a relevant belief. It may be that justice porn, in the sense indicated here, is actually a subset of moral outrage porn. We need not take a position on this issue, but if justice porn is simply an example of moral outrage porn, this fits nicely with the plausibility of the view that both moral outrage porn and justice porn are prime examples of cognitive porn.

Regarding using the "wrong kinds of reasons," see Hieronymi, “The Wrong Kind of Reason." 
virtues. ${ }^{30}$ And notice that this sort of unambiguous, strident morality does seem to be precisely the kind of moral system we often find in communities given to the endemic usage of moral outrage porn.

What, then, of those moral outrages that depend on one's antecedently accepted moral views? We already hold certain moral beliefs, and it is so tempting to indulge in those websites that hold up the enemies of our antecedent beliefs for outrage and disdain. There are two major problems with this behavior pattern. First, in most cases, independent confirmation is a good reason to increase our degree of belief. When we systematically seek out moral outrage porn, we are getting extra confirmations of our moral worldview. That confirmation works in several ways. One way relies on the fact that moral outrage porn can itself contain moral content. That is, much moral outrage porn does not simply represent some state of affairs neutrally, to which we apply our own moral beliefs-it instead presents the world already colored by moral judgment. Thus, it presents itself as a form of support for our moral beliefs. But when one is engaged with moral outrage porn, one is seeking out representations of moral outrage for the sake of the resulting gratification, and so one is incentivized to preselect those representations with which one agrees. This invites a problematic form of circularity-where one picks one's sources based on agreement with one's antecedent beliefs, and then goes on to use those sources to buttress one's antecedent beliefs. ${ }^{31}$ Thus, the moral outrage porn user is tempted, through the logic of self-gratification, into epistemic relationships that can increase their degree of moral self-confidence without adequate epistemic justification.

Second, moral outrage porn may misrepresent empirical facts about the world in order to provoke more gratifying moral outrage. This may happen by simply presenting false "facts," or by cherry-picking outraging facts. For example, a moral outrage porn news site could easily operate simply by selectively picking out the most damning and awful single sentences said by members of some opponent political party. Such cherry-picking offers an easier and more reliable pathway to the gratifications of moral outrage than would a more complete presentation of the relevant facts. Thus, such a site would misrepresent the

30 We are assuming, for the sake of this paper, the kinds of epistemic norms that demand that beliefs arise from the evidence, as guided by the aims of truth (Hieronymi, "The Wrong Kind of Reason"). We suspect that most pragmatist accounts of epistemic norms would also yield norms forbidding this sort of bad faith belief, on long-term pragmatic grounds, but that issue is beyond the scope of this paper.

31 For a discussion of how moral agreement and disagreement are epistemically relevant to moral beliefs, please see Nguyen, "Autonomy, Understanding, and Moral Disagreement." For further discussion about the social circularity described here, see Nguyen, "Cognitive Islands and Runaway Echo Chambers" and "Echo Chambers and Epistemic Bubbles." 
opponent party as a means of gratifying its audience. And the user of moral outrage porn, insofar as they seek that particular form of gratification, should prefer such poorer-quality sources of information to more accurate, but less gratifying, sources.

So far, we have been discussing nonfictional cases, which are the clearest cases of problematic moral outrage porn. They represent purportedly real situations, and consequently engage one's genuine moral beliefs and/or morally relevant empirical beliefs. But what about fictional cases? Surely we could have representations of moral outrage in fiction, and surely we could engage with fiction specifically for the gratifications of such representations. What could possibly be wrong with that?

First, it is important to note that we may not be able to actually adopt fictional moral attitudes. As the recent literature on imaginative resistance tells us, there seems to be a striking difference between moral beliefs and other beliefs in fiction. ${ }^{32}$ We can easily imagine ourselves into a fictional world in which ships travel faster than light or the Nazis won World War II. But we cannot easily imagine ourselves into a fictional world where the Nazis' anti-Semitism was morally correct or where killing innocents for sport is morally praiseworthy. This means that fictional moral outrage porn will have the following character: it will present us with fictional situations with which we engage on the basis of our actual moral beliefs. Again, one might ask, what's wrong with that? After all, we will not be changing our consumption of facts in the world, so we will not be engaged in epistemic bad faith.

The worry about strategically shifting one's moral beliefs to maximize outrage, however, remains. We engage with morally outraging fiction as non-porn when we are appropriately entangled with its moral content-when we ask ourselves if its moral vision is true, and, if it is, try to integrate that vision into our belief system. We engage with morally outraging fiction as porn when we take gratification from our reaction of moral outrage, while avoiding the further entanglements of applying and integrating our larger epistemic and moral beliefs with an eye toward the truth..$^{33}$ Furthermore, if a certain moral system is desirable, not because it is accurate but because it maximizes the pleasures of moral outrage, then that desirability will show up both in the fictional and the nonfictional cas-

32 Gendler, "The Puzzle of Imaginative Resistance."

33 We are not assuming here that the only content of fiction is moral content. For example, it seems to us that one can engage with fiction's artistic content in a way that is richly entangled with aesthetic and artistic engagement, or one can avoid such engagement, as Mag Uidhir and Levinson suggest. 
es. When this happens, the use of fictional moral outrage porn can incentivize us to acquire moral beliefs for the wrong reasons.

\section{THE MORAL STATUS OF MORAL OUTRAGE PORN}

We have argued that the use of moral outrage porn is often epistemically problematic. It seems to us, however, that using moral outrage porn might also be morally problematic. In this section, we will sketch some possible frameworks for thinking about the moral problems of moral outrage porn. While we do not take ourselves to be presenting complete arguments here, we find these lines of inquiry plausible and worthy of further development.

First, reconsider the epistemic connection. As we noted, in the vast majority of cases of the use of moral outrage porn, an individual will seek out representations that are pleasurable because of that individual's antecedent moral views, thereby acquiring what is easily mistaken for further confirmation of these views. This is certainly problematic in the epistemic sense. But epistemic carelessness is not, in itself, always morally problematic. (For example, suppose that we form our belief about whether tomatoes are fruits or vegetables by consulting our Magic 8 Ball. This is bad reasoning, epistemically speaking, but not morally wrong.)

It is plausible, however, that epistemic carelessness specifically in the moral realm is morally problematic. Insofar as one's moral convictions are likely to inform how one behaves in morally relevant settings, epistemic carelessness in the moral realm exposes one to acting in morally wrongful ways. Increasing the likelihood that one will act wrongfully is clearly morally problematic for consequentialist reasons, and epistemic carelessness in the moral realm may also be morally problematic simply in virtue of expressing a lack of respect for moral reasoning. ${ }^{34}$ Thus, because the use of moral outrage porn seriously risks violations of acceptable morally relevant belief formation, it is morally problematic.

Additionally, the use of moral outrage porn faces another, distinctively moral problem-one that is entirely independent of epistemic considerations. In discussions of moral outrage porn, we have noticed a common attitude, vaguely expressed as the concern that using moral outrage porn misuses morality-that such use "isn't what morality is for." This intuitive sense of wrongness, we think,

34 For our current purposes, it is enough that there is at least one serious moral strike against such epistemic carelessness. In an in-progress paper, however, Bekka Williams argues that nontrivial epistemic carelessness in the moral realm is morally wrong regardless of its consequences. 
points the way to the distinctively moral problem. The use of moral outrage porn cheapens and undermines the role of moral experience.

This worry parallels, in some significant ways, Tosi and Warmke's complaint against moral grandstanding. ${ }^{35}$ Moral grandstanding is morally problematic, they argue, in large part because grandstanders are treating moral discourse as a "vanity project":

In using public moral discourse to promote an image of themselves to others, grandstanders turn their contributions to moral discourse into a vanity project. Consider the incongruity between, say, the moral gravity of a world-historic injustice, on the one hand, and a group of acquaintances competing for the position of being most morally offended by it, on the other.

Such behavior, we think, is not the sort of thing we should expect from a virtuous person. ${ }^{36}$

Note, crucially, that the problem asserted by Tosi and Warmke in this instance is not that moral grandstanding has bad results. ${ }^{37}$ Instead, the problem is that using moral discourse for self-promotion is problematically egotistical.

Tosi and Warmke focus on moral problems associated with using moral outrage for interpersonal jockeying. That is the essence of the notion of moral grandstanding - the use of moral expression for social signaling. Similarly, it seems plausible that the use of moral outrage porn in many cases involves a failure to respect the fundamental role of moral expression. Notice that, where the problem with moral grandstanding is essentially interpersonal and social, the problem with moral outrage porn is personal and hedonistic. ${ }^{38}$ The problem of moral grandstanding is that we use morality for status; the problem of moral outrage porn is that we are using morality for pleasure. When one indulges in moral outrage porn, one uses what by one's own lights is morally outrageous for

As described by Tosi and Warmke, moral grandstanding involves expressing a moral view, attitude, etc., where the expression is significantly motivated by a desire to be recognized as "morally respectable" ("Moral Grandstanding," 200, 202).

Tosi and Warmke, "Moral Grandstanding," 215-16. Although they also claim that moral grandstanding often has bad results.

38 For empirical evidence that experience of moral outrage serves to reduce the experience of individual guilt, see Rothschild and Keefer, "A Cleansing Fire"; and Rothschild et al., "A Dual-Motive Model of Scapegoating." For empirical evidence that individuals sometimes engage with moral-outrage-inducing articles in order to bolster their self-perceptions as morally virtuous (as "paragons of morality"), see Green et al., "Self-Enhancement, Righteous Anger, and Moral Grandiosity.” 
one's own enjoyment. ${ }^{39}$ It is, loosely speaking, to make morality about oneself, when it clearly is not.

Furthermore, it is no accident, we think, that the features of moral outrage porn relevant to the "bad faith" problem mirror Michael Tanner's account of the problems of sentimentality. ${ }^{40}$ In his discussion of Oscar Wilde and the sentimental, Tanner says, "the feelings which constitute [the sentimental] are in some important way unearned, being had on the cheap, come by too easily." ${ }^{11}$ The use of moral outrage porn, if one accepts our definition, involves an attempt to be gratified by a representation of the end result of moral engagement without taking on the consequences or effort of actually engaging. This seems a paradigmatic case of getting a feeling on the cheap.

What we have sketched thus far are a number of considerations that weigh in favor of a serious moral strike against the use of moral outrage porn. There are also a number of consequentialist considerations that we might adduce. Tanner argues that the intrinsically sentimental tends toward passivity. ${ }^{42}$ Sentimental emotions, Tanner suggests, can themselves encourage inaction.

It also seems to me that some of my feelings are of a kind that inhibit action, because they themselves are enjoyable to have, but if acted upon, one would cease to have them, and one doesn't want to. Such a feeling does seem to me intrinsically sentimental. ${ }^{43}$

Just as sexual pornography can-although certainly need not-problematically replace real interpersonal sexual interaction, moral outrage porn runs the risk of mollifying its users into inaction. ${ }^{44}$ Along similarly problematic lines, use of moral outrage porn could have the effect that Tosi and Warmke term "outrage exhaustion"- that is, those who regularly use moral outrage porn may, as Tosi and Warmke suggest, "find it increasingly difficult to muster outrage when it actually is appropriate." ${ }^{45}$ But these final suggestions would require significant empirical investigation to substantiate.

See especially our above discussion of the difficulty (if not impossibility) of enjoying an instance of moral outrage porn without at least entertaining a relevant moral belief.

Tanner, "Sentimentality."

Tanner, "Sentimentality," 128.

Tanner, "Sentimentality," 134.

Tanner, "Sentimentality," 139.

See especially empirical findings by Rothschild and Keefer ("A Cleansing Fire") suggesting that the expression of moral outrage tends to decrease the experience of personal guilt, which thus tends to decrease motivation to act to remedy injustice.

Tosi and Warmke, "Moral Grandstanding," 211. 


\section{PORN AS INSTRUMENTALIZING}

This analysis of moral outrage porn suggests a larger account of the moral status of porn in general. Our comments here will necessarily be a bit preliminary, since we are grappling with a large and diverse array of phenomena.

As we noted earlier, users are looking for pornography to provoke a mechanistic and simplistic response in them-unlike the complex, unpredictable, and rich responses we seek with art. That mechanistic attitude reveals something deeper: an instrumental attitude toward the pornography. This instrumentalization seems problematic in two ways. Insofar as art is intrinsically valuable, then pornography cannot be art, because our attitude toward it is strictly instrumental. And insofar as the frequent use of pornography encourages a strictly instrumental attitude toward actual people and sexual encounters, then it helps to undermine our capacity to treat humans and intimate human relationships with the dignity they deserve.

Moral outrage porn also involves various forms of problematic instrumentalization. First, with moral outrage porn, we are instrumentalizing the porn's content-though not through the kind of mechanistic pathway of sexual pornography. Insofar as I am interacting with the news as moral outrage porn, I am not looking to be informed by the facts, but am using the news for the sake of my own gratification. So long as we are supposed to be responsive to the genuine facts of the matter, using the news as moral outrage porn-and manipulating which facts I am exposed to, for the sake of gratification - is a violation of epistemic norms. Furthermore, the regular use of moral outrage porn encourages a further form of instrumentalization-one in which we instrumentalize our own moral beliefs. Moral outrage porn gives me an incentive to modify my own moral beliefs: I can be tempted to modify my beliefs to make it easier to access the gratifications of moral outrage. But that modification is an abuse of moral belief-so long as we think that moral beliefs are supposed to track something like moral truth.

This suggests a general account of the moral status of porn. Using porn involves making an instrumental use of a representation. Furthermore, using porn often encourages further instrumentalizations of the represented content. ${ }^{46} \mathrm{Fi}$ nally, using porn often encourages even more downstream instrumentalizations of various background beliefs and attitudes. For example: using sexual pornog-

46 Consider especially Green et al.s evidence that those who have been manipulated to experience moral outrage ("righteous anger") had an increased likelihood of desiring to engage with moral-outrage-inducing articles ("Self-Enhancement, Righteous Anger, and Moral Grandiosity"). 
raphy certainly instrumentalizes representations of sex and bodies, may encourage the instrumentalization of sex and bodies themselves, and may encourage the instrumentalization of downstream associates, such as relationships and personalities. ${ }^{47}$ Using the news as moral outrage porn certainly instrumentalizes the news, likely instrumentalizes the events in the world, and furthermore may encourage the instrumentalization of our moral beliefs and moral communities.

This helps us explain the variation in our attitudes toward the moral status of different kinds of porn. Other things being equal, the use of porn is morally problematic when such instrumentalizations run afoul of other norms (some of which we have discussed), and unproblematic when such instrumentalizations are themselves unproblematic. This offers a useful explanation for our asymmetric intuitions about the various forms of porn. Using food porn and real estate porn seems unproblematic. Our account suggests that this is because there is nothing wrong with instrumentalizing food or real estate or their representations. Sexual pornography and moral outrage porn strike many as problematic. Our account suggests an explanation: they are problematic insofar as they encourage the instrumentalization of things that ought not to be instrumentalized.

To be absolutely clear: our account is in no way intended to be a criticism of moral outrage, or some sort of general call for politeness and civility. Moral outrage can be crucial to proper moral action and the quest for social justice. Our worry is, in fact, something of the opposite: our worry is that using moral outrage porn can dilute genuine moral outrage or lead it astray. It is precisely because moral outrage is so important that we must not instrumentalize it. We certainly should not retune our sense of outrage for our own pleasure.

It might be useful here to note that there can certainly also be "civility porn": calls for civility and politeness, used for the sake of pleasurable feelings of, say, smugness and superiority at one's own maturity and high-mindedness. ${ }^{48}$ The problem is not with moral outrage or civility themselves; it is with instrumentalizing the representations of either. Both moral outrage and civility are vital, which is exactly why moral outrage porn and civility porn are so potentially undermining.

\section{CONCLUSION}

We think that our definition captures, to a significant degree of accuracy, the natural usage of the term porn in the generic sense. It describes the regular way in

47 For a sophisticated discussion of the potential harms of sexual pornography, see Eaton, "A Sensible Antiporn Feminism."

48 We owe this idea to a suggestion by Aaron Rabinowitz. 
which the term has come to be used and understood in recent discussions, and it naturally categorizes sexual pornography as an instance of generic porn-which is both plausible on its face and helpful in explaining the genesis of the generic usage. Furthermore, our account of generic porn is useful in that it highlights and provides a framework for discussing a widespread and rapidly increasing phenomenon: moral outrage porn. The use of moral outrage porn, we have argued, is epistemically problematic. It may also be morally problematic. It is plausibly objectionable in the way that cheapens and undermines moral experience. Moral outrage porn invites us to instrumentalize something that ought not to be instrumentalized.

We have tried to unpack the conceptual insight contained in a recent, naturally evolved sort of neologism. The term "porn" once had a clear and restricted meaning, concerning certain sexual representations. That term has recently gained a new, secondary colloquial usage - the generic usage of "porn." That usage may have started as a metaphor or a joke. But the reason that this secondary usage has caught on so well is because it identifies a common thread in our usage of representations - that sometimes we use representations for self-gratification, freed from the usually attendant consequences and worries that might accompany actual interactions with what was represented. That kind of usage is starkly obvious in the sexual cases, but thinking seriously about the use of sexual pornography, as we have argued, provides a very useful framework for understanding the new and widespread use of the term "porn" in the generic sense. ${ }^{49}$

University of Utah thi.nguyen@gmail.com

Minnesota State University, Mankato bekka.williams@mnsu.edu

49 We would like to thank, for all their assistance, Brandon Cooke, Hans Maes, Alex Neill, and Aaron Rabinowitz. We have also benefited from, and very much appreciate, the feedback we received from attendees at the viII Braga Meetings on Ethics and Political Philosophy, where an early version of this paper was presented in 2017. 


\section{REFERENCES}

Abcarian, Robin. "Is Aziz Ansari a Victim of 'Revenge Porn' or a Perpetrator?" Chicago Tribune, January 17, 2018. http://www.chicagotribune.com/news/ opinion/commentary/ct-perspec-victimhood-aziz-ansari-revenge-sexual -aggression-weinstein-lauer-charlie-rose-o118-story.html.

Davies, David. "Pornography, Art, and the Intended Response of the Receiver." In Maes and Levinson, Art and Pornography, 61-82.

Doucet, Brian, and Drew Philp. “In Detroit 'Ruin Porn' Ignores the Voices of Those Who Still Call the City Home." The Guardian, February 15, 2016. https://www.theguardian.com/housing-network/2016/feb/15/ruin-porn -detroit-photography-city-homes.

Eaton, A.W. "A Sensible Antiporn Feminism." Ethics 117, no. 4 (July 2007): 674715 .

Flanagan, Caitlin. "The Humiliation of Aziz Ansari." The Atlantic, January 14, 2018. https://www.theatlantic.com/entertainment/archive/2018/o1/the -humiliation-of-aziz-ansari/550541/.

Gendler, Tamar Szabó. “The Puzzle of Imaginative Resistance.” Journal of Philosophy 97, no. 2 (February 2000): 55-81.

Green, Jeffrey D., Constantine Sedikides, Daryl R. Van Tongeren, Anna M. C. Behler, and Jessica M. Barber. "Self-Enhancement, Righteous Anger, and Moral Grandiosity." Self and Identity 18, no. 2 (December 2017): 201-16.

Ham, Mary Katharine. "Ansari Isn't the First Victim of \#MeToo Revenge Porn, but He Should Be the Last." The Federalist, January 17, 2018. http://thefederalist.com/2018/o1/17/aziz-ansari-isnt-the-first-victim-of-metoo-revengeporn/.

Hieronymi, Pamela. "The Wrong Kind of Reason." Journal of Philosophy 102, no. 9 (September 2005): 437-57.

Kania, Andrew. "Concepts of Pornography: Aesthetics, Feminism, and Methodology." In Maes and Levinson, Art and Pornography, 254-76.

Levinson, Jerrold. "Erotic Art and Pornographic Pictures." Philosophy and Literature 29, no. 1 (April 2005): 228-40.

Maes, Hans. "Who Says Pornography Can't Be Art?” In Maes and Levinson, Art and Pornography, $17-47$.

Maes, Hans, and Jerrold Levinson, eds. Art and Pornography: Philosophical Essays. Oxford: Oxford University Press, 2012

Mag Uidhir, Christy. "Why Pornography Can't Be Art." Philosophy and Literature 33, no. 1 (April 2009): 193-203.

Miller, Boaz, and Isaac Record. "Justified Belief in a Digital Age: On the Epis- 
temic Implications of Secret Internet Technologies." Episteme 10, no. 2 (June 2013): 117-34.

Nagel, Thomas. "Sexual Perversion." Journal of Philosophy 66, no. 1 (January 1969): 5-17.

Neill, Alex. "The Pornographic, the Erotic, the Charming, and the Sublime." In Maes and Levinson, Art and Pornography, 48-60.

Nguyen, C. Thi. "Autonomy, Understanding, and Moral Disagreement." Philosophical Topics 38, no. 2 (Fall 2010): 111-29.

—. "Cognitive Islands and Runaway Echo Chambers: Problems for Epistemic Dependence on Experts." Synthese 197 (2020): 2803-21.

- "Echo Chambers and Epistemic Bubbles." Episteme 17, no. 2 (June 2020): 141-61.

Pariser, Eli. The Filter Bubble: What the Internet Is Hiding from You. London: Penguin Books, 2011.

Patridge, Stephanie. "Exclusivism and Evaluation: Art, Erotica and Pornography." In Pornographic Art and the Aesthetics of Pornography, edited by Hans Maes, 43-57. Basingstoke: Palgrave Macmillan, 2013.

Pizarro, David A., and Roy Baumeister. "Superhero Comics as Moral Pornography." In Our Superheroes, Ourselves, edited by Robin S. Rosenberg, 19-36. New York: Oxford University Press, 2013.

Rea, Michael C. "What Is Pornography?” Noûs 35, no. 1 (March 2001): 118-45.

Rothschild, Zachary K., and Lucas A. Keefer. "A Cleansing Fire: Moral Outrage Alleviates Guilt and Buffers Threats to One's Moral Identity." Motivation and Emotion 41, no. 2 (April 2017): 209-29.

Rothschild, Zachary K., Mark J. Landau, Daniel Sullivan, and Lucas A. Keefer. "A Dual-Motive Model of Scapegoating: Displacing Blame to Reduce Guilt or Increase Control." Journal of Personality and Social Psychology 102, no. 6 (June 2012): 1148-63.

Schopenhauer, Arthur. The World as Will and Representation. Translated by E. F.J. Payne. New York: Dover Publications, 1969.

Scruton, Roger. "The Moral Birds and the Bees." National Review, September 15, 2003. https://www.catholiceducation.org/en/controversy/marriage/the -moral-birds-and-the-bees.html.

Steiner, George. "Night Words: High Pornography and Human Privacy." In The Pornography Controversy: Changing Moral Standards in American Life, edited by Ray C. Rist, 203-16. New Brunswick, NJ: Transaction Books, 1975.

Tanner, Michael. "Sentimentality." Proceedings of the Aristotelian Society 77 (1976-77): 127-47.

Threadgold, Steven. “'Struggle Street' Is Poverty Porn with an Extra Dose of 
Class Racism." The Conversation, May 5, 2015. https://theconversation.com/ struggle-street-is-poverty-porn-with-an-extra-dose-of-class-racism-41346.

Tosi, Justin, and Brandon Warmke. "Moral Grandstanding." Philosophy and Public Affairs 44, no. 3 (Summer 2016): 197-217.

Watson, Jamie Carlin. "Filter Bubbles and the Public Use of Reason: Applying Epistemology to the Newsfeed." In Social Epistemology and Technology: Toward Public Self-Awareness Regarding Technological Mediation, edited by Frank Scalambrino, 47-57. London: Rowman and Littlefield, 2015. 